\title{
The Development and Status of Automobile E- Commerce in China
}

\author{
Lingli Gan ${ }^{3}$ and $\mathrm{Lu} \mathrm{Liu}^{2}$ \\ 'Ningbo Institute of Technology, Zhejiang University, Ningbo 315100, Zhejiang, P.R. \\ China \\ ${ }^{2}$ Department of Information System, Beihang University, Beijing100083, P.R. China \\ ganlingli@nit.zju.edu.cn
}

\begin{abstract}
Although the hype surrounding the promise of electronic commerce seems all pervasive currently, there is an absence of research on automobile eCommerce, especially in developing countries, which covers wide-ranging issues beyond contextual imperatives. This paper tries to fill in the gap, by analyzing the impacts of eCommerce on automobile industry in China, and the factors of eCommerce adoption and development of automobile industry in China from internal, external and contextual perspectives, after describing the internet and ecommerce in china. From the situation of automobile ecommerce in China, the paper finds that the automobile industry in China, especially automobile sales, remains only superficially affected by the ecommerce. This is a big difference from the developed countries such as U.S. The paper also displays the important aspects to the development of automobile ecommerce in China such as infrastructure, role of the central government, serving the customer better, security, customer trust, delivery, and so on.
\end{abstract}

Keywords: E-commerce ,E-business, China, Enterprise information system, Enterprise management, Virtual Enterprises, Strategic Information Systems, Automobile industry

\section{INTRODUCTION}

The introduction of the Internet is one of the great revolutions of our time, and there is a growing interest in the use of e-commerce as a means to perform business transactions over the Internet. The new eCommerce technologies have proven to be tremendous sources of economic growth for the more advanced industrialized economies of North America, Europe, and Asia. Few organizations today debate whether to participate in e-commerce.

Organization for Economic Co-Operation and Development (OECD) officially acknowledges electronic commerce (EC) as a new way of conducting business [1]. In this report, OECD recognizes that $\mathrm{EC}$ has the potential to radically alter economic activities and the social environment. Particularly, the enormous growth of EC along with the rapid development of information technology (IT) is having a profound impact 
on the world economy. Accordingly, EC is considered to be an unavoidable alternative for companies of the 21 st century $[2,3]$.

While ecommerce has been subjected to a wide range of definitions in its comparatively short history, for the purposes of this paper, eCommerce is defined as 'electronic commerce includes any form of business activity conducted via electronic means, which might range from products/services information to selling and/or buying products' by Wigand [4] and Kalakota and Whinston [5]. Thus defined, electronic commerce would include business-to-business, and business-to-end consumer transactions and information provision over the Internet. After all, the horizon of EC expands as the conduct of selling, buying, logistics, or other organization-management activities via the Web [6]. Undoubtedly, E-commerce is not only the buying and selling of products via electronic means, it involves all other activities to support the sale process. E-commerce is changing the business process, and it is also changing the organizational structure and their customers to support the new process.

As eCommerce evolves, a lot of papers reveal its adoption and development. The literature on eCommerce adoption by businesses suggests that most research is based on five frameworks: (1) The diffusion of innovation; (2) The Technology-OrganizationEnvironment Model (TOE); (3) Institutional theory; (4) Resource-based theory; (5) Perceived eReadiness Model [7, 8].

However, there is shortage of research on automobile ecommerce in developing countries, not only from a theoretical perspective but also from an empirical viewpoint, while the automobile industry play a increasingly important role on the economic and social aspects of the world. The paper focuses on the ecommerce's impacts on Chinese automobile industry and the development of automobile ecommerce in china. The following parts are internet in china, eCommerce in china, impacts of e-commerce on automobile sector in China, and factors of the development of automobile e-commerce in China.

\section{INTERNET IN CHINA}

As shown in Table 1, Internet use has experienced explosive growth in China, as gauged by several key indicators of Internet development.

Table 1. Internet Development in China, 1997-2006

\begin{tabular}{|c|c|c|c|c|c|}
\hline & $\begin{array}{l}\text { Number } \\
\text { of Internet } \\
\text { users }\end{array}$ & $\begin{array}{l}\text { Number } \\
\text { of domain } \\
\text { names } \\
\text { registered }\end{array}$ & $\begin{array}{l}\text { Number } \\
\text { of .com\& .c } \\
\text { om.cn } \\
\text { domain } \\
\text { names } \\
\text { registered }\end{array}$ & $\begin{array}{c}\text { Number } \\
\text { of websites }\end{array}$ & $\begin{array}{l}\text { Internati } \\
\text { onal } \\
\text { bandwidth } \\
\text { (Mbp) }\end{array}$ \\
\hline $\begin{array}{c}\text { October } \\
1997\end{array}$ & 620,000 & 4066 & 2131 & 1500 & 25 \\
\hline $\begin{array}{c}\text { June } \\
2006\end{array}$ & $\begin{array}{l}123,000, \\
000\end{array}$ & $2,950,00$ & $1,435,76$ & 788,400 & 214,175 \\
\hline
\end{tabular}

Source of data: adapted from [9] 
From the above table, given the fact that China is a developing country, there are a surprisingly high percentage of Internet users among Chinese both individuals and firms as compared to results from developed countries. As time passes, the Internet's role in business is gradually shifting from one of gaining an additional advantage over competitors to one of necessity, i.e., firms need to become Internet users just to avoid being overtaken by others, rather than to get ahead of others, as may have been the case in the early days of e-commerce.

With her WTO accession in 2001 and her general economic and social development, China is rapidly emerging as a major exporter in the world economy, and as a result it is not surprising that more and more Chinese firms are using the Internet to tap the international market.

\section{E-COMMERCE IN CHINA}

The concept eCommerce emerged in China in 1993, when the foreign businesses in China started to use EDI to simplify trading processes [10]. With the access of the country's first network (the National Computing and Networking Facility of China) to the global Internet in 1994, and the establishment of the China International Electronic Commerce Center to research and promote digital business by The Ministry of Trade and Economic Cooperation in 1996, internet-based eCommerce was launched in China in 1997.

The development of Chinese e-commerce can be divided into four stages: "Initiation" (1993-1995); "Contagion" (1995-2000); "Cooling" (2000-2004), and "Permeation" (2004 onwards). By 2004, in the "Permeation" Phase, the total number of Internet-users in China had grown to 94 million, making China the second largest Internet user market in the world [11]. The adoption of the Internet is largely concentrated within the ten most developed provinces and autonomous municipalities, mostly along the East Coast [11]. There were 0.67 million websites in China in 2004, of which $60.7 \%$ were corporate websites. Most corporate websites provide sections "About the Company (85.3\%)" and "Products (81.9\%)". For other information, $56.6 \%$ have "Events", $40.0 \%$ have "Contact Us", 36.1\% have "Product Search", $18.6 \%$ have "Online Query" and $12.7 \%$ have "Virtual Community". Just over half $(50.9 \%)$ of company websites have an online database [12].

The growing number of Internet users and cyberbuyers has provided an opportunity for eBusiness development in China. The first on-line sale in March 1998 symbolised the beginning of China's e-Commerce. US $\$ 40$ million were generated in 1999 in China, opposed to US $\$ 8$ million in 1998 . The total value of consumer on-line purchasing reached US\$38.6 million in 2000 . EBay, the US on-line auction giant, estimates that China's e-Commerce revenue will reach more than US\$16 billion in the near future. Moreover, according to Easyspace Ltd. Company, the market's value is projected to expand to US $\$ 23$ billion within 3 years, in contrast to the current value of US\$500 million per year.

The main reasons for Chinese Internet users shopping on-line are time-saving, lower costs, easy to use and looking for rare goods; and around $22 \%$ of the buyers purchase out of curiosity. They often purchase books, CDs and computer appliances from the net. 
Meanwhile, Chinese consumers, who have no tax incentives to shop online and little legal recourse if the transaction goes wrong, will be reluctant to abandon traditional marketplaces where they can enjoy a social experience and engage in time-honored rituals such as haggling or asking for special deals.

Moreover, the environment for e-commerce is very challenging, although traditional commerce, both at the retail level and between companies, also remains comparatively inefficient in China. The personal nature of business relationships, the informality of information, and the lack of separation between political and economic actors are among the factors inhibiting and shaping the development of e-commerce, especially of B2B mode, in China. In addition, the prospects for e-commerce in China are related to the development of the rules and infrastructure that are fundamental to a modern market economy. The fundamental premise is that faceless market transactions enabled by ecommerce will improve economic efficiency and the quality of life.

No matter what it be, in China, e-commerce may not only enhance efficiencies at the firm or supply chain level, but also serve as a catalyst for hastening the development of the fundamental rules and infrastructure needed for market-based commerce.

\section{IMPACTS OF E-COMMERCE ON AUTOMOBILE SECTOR IN CHINA}

Many pundits have forecast enormous impacts from electronic commerce in most industry sectors, predicting momentous changes in the world of commerce as we know it today. The interconnectivity and pervasiveness of the Internet do open new possibilities for the organization of work, for the management of the supply chain and formation of dynamic trading networks, and for entrepreneurs to meet the needs and demands of ever-better informed consumers. However, the extent of the impacts of electronic commerce in automobile industry (retailing) remains somewhat difficult to predict with accuracy: conservative estimates suggest that Internet shopping may ultimately account for $10-15 \%$ of the retail sector [13].

The car industry has traditionally relied on a supply chain. Car manufacturers (typically fairly large, prominent organizations) draw raw materials and other component parts from a number of suppliers. Finished new cars are then distributed to a network of car dealers, for on-selling to the end consumer. End consumers may sell used cars back to dealers (perhaps as a trade-in on another car, although not necessarily), or alternatively, may privately organize sales of used cars direct to other end consumers.

Currently, some car purchasers are using the Internet to research vehicle types and features, and to identify and locate vehicles potentially of interest. Having made a decision about the make and model of car(s) in which they are interested, typically these consumers then go about transacting the rest of their car purchase in the more traditional manner. Most of the remaining Internet-influenced purchasers used the Internet to locate a dealer stocking the particular type of vehicle they are interested in. At the moment, almost no complete sales are made over the Internet, nor are additional arrangements such as finance, insurance and additional warranty options generally made over the Internet. 
Most large car dealerships, particularly those with annual revenues of greater than $\$ 10$ million per year, have an Internet presence or plan to have one in the near future. The smaller players in the industry are also either established on the Web, or are planning to become so in the foreseeable future. The web presence is usually accomplished through the electronic malls or marketplaces which were briefly outlined previously when discussing changes to the car retail industry supply chain.

Despite each of the car dealerships having web sites, the business processes of each dealership were not well integrated with the web site. All the car yards had wellestablished mechanisms for handling new 'walk/phone-in' customer enquiries, but they were somewhat concerned about how equitably, efficiently and effectively to deal with e-mails generated from on-line buying services. Generally speaking, they had not carefully thought out appropriate business processes to handle Internet enquiries.

Already in the China car retailing industry, electronic commerce has seen the advent of on-line listing and buying services, acting as a conduit of information, referrals and expressions of interest between end consumers and new and used car dealers. Thus dealers register with these on-line buying services, regularly providing updates on the range and features of vehicles they have available for sale. In exchange, the on-line service providers facilitate placing interested customers in touch with the relevant dealer.

The Internet would not be a medium over which actual sales would take place, but might be a medium which would influence buyers in terms of which car dealerships that they approached. The situation regarding the Internet and car retailing in China seemed to be one of great uncertainty and some anxiety on the part of the car dealerships. Many dealers generally acknowledged that electronic commerce and the Internet could become enormously important to their businesses, although they were uncertain as to exactly what impacts it might have, how dramatic these impacts would be, and on how these changes might be realized in their specific businesses. Comparatively few of the dealers believed that the car industry would ever achieve the state where transactions are completed on-line. Despite the skepticism, few of the car dealers were willing to completely ignore electronic commerce at the moment. Rather, the articulated strategy was 'We have to be on the Web, because otherwise we might miss out'.

The car industry in China thus remains only superficially affected by the technology and presence of the Internet. Each of the major car dealerships has web sites, albeit on electronic malls which seem very much like the forerunners of the powerful Internet buying services of the USA. However, cars are not selling over the Internet, and apparently in the eyes of the car dealers, people's buying behavior is not being influenced by the Internet. CEOs and senior managers are back to the main job of selling cars as usual.

It could be argued that the US experience with electronic commerce seems several years in advance of China with respect to its acceptance and adoption of on-line retailing, and given reasonable similarities in business trends between the USA and China, it could provide a useful model for local businesses to consider in order that they can prepare for the future. 


\section{FACTORS OF THE DEVELOPMENT OF AUTOMOBILE E- COMMERCE IN CHINA}

\subsection{Infrastructure}

In discussing the e-commerce future, many experts have assumed that it in emerging markets will evolve along the same lines as it has in the US, North America, and to a great extent, in Western Europe. This assumption fails to take into account the differences that exist between the economic infrastructures of emerging markets and those developed markets of the West. This infrastructure has been an extremely influential technological externality that has benefited the e-commerce industry beyond measure.

E-commerce in the West has developed as it has, because an existing distribution, financial, and communications infrastructure conducive to e-commerce already existed. In more-developed economies, advanced communication and computer technologies are pervasive, distribution and warehousing networks are generally extensive, fast, and reliable, and though exceptions such as Japan exist, financial/credit networks are readily available and efficient.

The infrastructures of most emerging markets is much less highly developed than the industrial West's, and will influence the development of e-commerce in China. In emerging markets such as China there are considerable difficulties in implementing the standard US model that many people in the West assume will dominate when they discuss e-commerce or make prognostications about it. However, local markets may determine that, given local conditions, alternative models may be preferable, especially when dealing with the more rational and economically driven business-to-business markets.

These technologies, and the skilled work forces necessary to employ them, provide the infrastructure needed to make the new-economy technologies so powerful. Additionally, this infrastructure has largely preceded in existence the Internet technologies that have made such powerful use of them. Unfortunately, these infrastructural elements do not exist in most emerging economies.

The developed economies' preexisting infrastructures permitted the Internet and its related Web-based technologies to create the fantastic cost reductions, increases in productivity, and potential for more that it has in advanced economies. The established infrastructure also permits the private sector to take the fullest possible advantage of the new-economy technologies. In emerging economies, can the same benefits be generated? From our perspective, how can the private sector develop the kind of actual and expected returns in emerging economies from Internet-based business strategies that it has in developed economies?

\subsection{Role of the Central Government}

The direct intervention of the central government is important to promote technological innovation [14], i.e. the Internet. Enabling government policies, such as trade and telecommunications liberalization, are likely to have the biggest impact on the adoption of e-Commerce. Government policies make Internet access more affordable, as well as increase pressure on businesses to adopt eCommerce to compete [15]. 
The Government is providing guidance on policymaking, financial investment, infrastructure development, education, human resources development, market transforming and service improvement. Polices, laws and regulations for the governing of telecom, Internet services, electronic information and other service areas that provide the technical platform for eCommerce were enacted recently.

It is argued that in developing countries governments play important roles in Internet development $[16,17]$. The Internet rapid development in China to a large extent can also be attributed to favorable government policies aimed at promoting Internet use by both individuals and businesses. As early as 1993, the Chinese government launched the Golden Project, with its aim being, among others, to build a national information highway and to promote the development of information technology in China [18].

Moreover, the Chinese Ministry of Labour and Social Security introduced the Professional Standards for eCommerce Specialists and the Regulation on National Licensing Procedure in 2001 to ensure the qualification of eCommerce specialists [19]. In 2005 , the State Council issued the first national guideline dealing specifically with eCommerce development, Some Opinions on Speeding up the Development of eCommerce, in which the government decided to take measures in five areas: 1. legal environment; 2. supporting industries; 3 . enterprise information; 4. technical support; 5. international cooperation [20].

With infrastructure development rapidly moving forward, the Chinese government also promulgated the Key Informatization Program of the 10th Five-Year Plan on National Economy and Social Development, which was intended to further promote the emergence of an information society. To promote the adoption of ecommerce, the Electronic Signature Law was passed by the Standing Committee of the 10th National People's Congress [9]. Therefore, against this backdrop of dynamic growth of Internet diffusion in China, the pattern of using the Internet to conduct e-commerce by Chinese businesses will inevitably change.

However, although the government aims to promote IT-enabled economic development, its Internet policies have the potential to inhibit business innovation. Considerable tension exists between promoting the Internet and restricting its use. For some reasons, e.g., safeguard national security and access to politically harmful information, the Government has to control, censor and monitor some aspects of the Internet, and the international gateway, which connects China to the World Wide Web.

In summary, the increasing number of Internet users and Government guidelines promoting adoption of Internet Technology in companies is facilitating the development of eCommerce in China. However, Government control and restrictions, as well as the lack of legal regulation, is a source of considerable tension and may impede its further development.

Furthermore, the policy implications of this is that, to get more Chinese businesses online, governments should provide educational programs to familiarize them with how to use the Internet to conduct business and the potential benefits thereof. In addition, both governments and Internet service providers should attempt to find ways to offer low-cost Internet access to small firms to help them get over the threshold.

The government is more effective to deal with some factors (e.g., infrastructure) than private firms. A final question thus is: what is the optimum level of involvements for government and private organizations in combating various barriers. 


\subsection{Customer Trust}

Trust plays an important role in many social and economic interactions involving uncertainty and dependency. Since uncertainties exist in transactions over the Internet, many researchers have stated that trust is a critical factor influencing the successful proliferation of e-commerce [21].

The concept of trust is crucial because it affects a number of factors essential to online transactions. Moreover, although e-commerce brings benefits to both vendors and customers, it also has limitations, such as the physical separation between buyers and sellers, and between buyers and merchandise. In order to reduce the barriers, vendors must develop a trustworthy relationship to foster customer loyalty.

System assurance of a Web vendor is a unique determinant of consumer trust and has the strongest influence on consumer trust among all the antecedents of trust across countries.

In order to encourage consumers to conduct transactions online, vendors also need to use various strategies to build trust. For example, vendors should provide prompt delivery, better after-sales service, and more accurate product information. Vendors should also make an effort to decrease consumers' risk perception to promote online purchase.

\subsection{Serving the Customer Better}

One reason why automobile sites, in general, may attract only $2 \%$ of sales is, very often, due to their poor design and user-unfriendliness. Companies should ensure that product categories are how the customer perceives them, not how company understands them. Again, the customer needs to be in focus.

Automobile companies need to take a look at the sites of some leading PC companies, which reveal a few basic elements that are simply missing from many of automobile sites. Compared with these PC sites, many automobile sites tend to be slow to respond; product descriptions revolve around convoluted type codes, often with no photos; there is no additional product information; and easy-access hotlines are generally non-existent. More importantly, customers take a slow and deliberate decision on the purchase of cars which are costly luxuries to them. Now we can start to answer why many automobile sites make very few sales online, unlike many electrical and mechanical products such as books, CDs and PCs.

\subsection{Security}

Security is the second major concern for Chinese eCustomers. Around $30 \%$ worry about the security of pay on-line recent years, opposed to $50 \%$ in 1998 . This worry will continue to be an issue for e-Commerce given the fact that American consumers are still concerned with security after so many years of extensive acceptance of Internet and e-Commerce with functional and reliable banking infrastructure [22].

Despite of the wide recognition that the unsophisticated pay and delivery infrastructure hinder e-Commerce developments in China, Chinese Internet users do not seem to be troubled with payment modes available for on-line purchases. The percentage of users complaining that the payment methods are inconvenient has been declining, The downward trend seems to mirror and support BDA-China's argument that the lack of sophisticated payment systems does not pose a major obstacle to 
China's e-Commerce, because its cash-on-delivery system is a reliable and popular means of payment for on-line purchases [22]. This may also suggest that the on-line payment system will soon not be a main obstacle to China's e-Commerce development.

\subsection{Delivery}

Furthermore, around $10 \%$ of Internet users perceive goods delivery being slow in China. The percentage has been decreasing since 2001. This may hint that postal services in the country generally satisfy customers and on-line merchants. Efendioglu and Yip [22] comment that the emerging private courier companies in China and the contracts between China's postal service and on-line merchants for goods delivery significantly minimize the distribution challenge for the eBusinesses.

\section{CONCLUSIONS}

Our study tries to explore the situation and development of automobile ecommerce in china, in order to obtain some points of further development and better future of automobile industry in china by reducing the gap with developed countries. For most automobile dealers, after a small burst of activity in establishing a web site so as to be prepared for electronic commerce, they has gone quiet. They are, however, quietly anxious about what might happen next week, in the next year or so, or next decade on the Internet in their industry. It remains to be seen how automobile e-commerce will develop in China and what role it will play in the economic development of the world's most populous country.

To push the development of automobile ecommerce in china, the following factors must be taken into serious and heavy considerations: infrastructure, role of the central government, serving the customer better, security, customer trust, delivery, and so on.

What is needed is some reflective thinking and some action planning with respect to electronic commerce. If the US experience is a guide as to what will happen in China, then it would seem timely to plan and enact the reengineering of business processes such that the Internet and associated internal systems are well integrated with the selling processes integral to the business. However, the different socio-cultural issues should be taken into account in the process of learning from U.S. experience.

\section{REFERENCES}

1. Anonymous, The Economics and Social Impact of Electronic Commerce, $\mathrm{OECD}$ (Organization for Economic Co-operation and Development) report (1999).

2. N.R. Adam, O. Dogramaci, A. Gangopadhyay, and Y. Yesha, Electronic Commerce: Technical, Business, and Legal Issues (Prentice-Hall: Upper Saddle River, NJ, 1999).

3. J.C. Westland, C. Clark, and H.K. Theodore, Global Electronic Commerce: Theory and Case Studies (The MIT Press: Cambridge, MA, 1999).

4. R. Wigand, Electronic commerce: definition, theory, and context, The Information Society. Number 13, pp.1-16, (1997). 
5. R. Kalakota and A.B. Whinston, Electronic commerce -A manager's guide (AddisonWesley Longman: Massachusetts, 1997)

6. G.P. Schneider, New Perspectives on E-Commerce, Course Technology (Boston, MA, 2002)

7. A. Molla, P.S. Licker, eCommerce adoption in developing countries: a model and instnument, Information \& Management. Volume 42, pp.877-899, 2005).

8. A. Molla and P.S. Licker, Perceived E-Readiness factors in Ecommerce adoption: an empirical investigation in a developing country, International Journal of Electronic Commerce. Volume 10, Number 1, pp.83-110, (2005).

9. CNNIC (China Internet Network Information Center), Statistical reports on the Internet development in China. http://www.cnnic.-net.cn/en/index/00/02/index.htm/ (Accessed August, 2006).

10. X. Du, Internet adoption and usage in China, in Proceedings of the 27th Annual Telecommunications Policy and Research Conference (Alexandria, VA, 1999).

11. J.J.H. Zhu and E. Wang, Diffusion, use, and effect of the Internet in China, Communication of the ACM. Volume 48, Number 4, pp.49-53, (2005).

12. CNNIC, China Internet and Information Resources Investigation Report 2004. http://www.cnnic.cn/ (Accessed August, 2005).

13. J. Reynolds, The Internet as a strategic resource: evidence from the European retail sector, Managing IT as a Strategic Resources, eds. I.L. Willcocks (McGraw Hill: London, 1987).

14. A.H. Seyal, M.M. Awais, S. Shamail, and A. Abbas, Determinants of electronic commerce in Pakistan: preliminary evidence from small and medium enterprises, Electronic Markets. Volume 14, Number 4, pp.372-387, (2004).

15. J. Gibbs, K.L. Kraemer, and J. Dedrick, Environment and policy factors shaping global eCommerce diffusion: a cross-country comparison, The Information Society. Volume 19, pp.5-18, (2003).

16. G.E. Burkhart, S.E. Goodman, A. Mehta, and L. Press, The Internet in India: better times ahead? Communications of the ACM. Volume 41, Number 11, pp.21-26, (1998).

17. B. Petrazzini and M. Kibati, The Internet in developing countries, Communications of the $A C M$. Volume 42, Number 6, pp.31-36, (1999).

18. Anonymous, The golden project. http://www.china.org.cn/chinese/zhuanti/283721.htm/ (Accessed August, 2006).

19. M.D. Yuan, Exploration on the solutions to B2B e-Commerce development in China, Gansu Agriculture. Number 8, pp.90-91, (2005).

20. Alamusi, Explanation on e-Commerce policy, E-BusinessWorld. Volume 4, pp.68-70, (2005).

21. D. Gefen, E-commerce: the role of familiarity and trust, Omega. Volume 28, Number 6, pp.725-737, (2000).

22. A.M. Efendioglu and V.F. Yip, Chinese culture and e-commerce: An exploratory study, Interacting with Computers. Volume 16, Number 1, pp.45-62, (2004). 